\title{
Department of Geoinformatics and Applied Computer Science
}

\author{
Monika Chuchro, Andrzej Leśniak
}

\section{INTRODUCTION}

The Department of Geoinformatics and Applied Computer Science is an organizational unit of the Faculty of Geology, Geophysics and Environmental Protection, AGH University of Science and Technology in Krakow. The unit was formed in 2003 as a Department of Informatics in Earth Science in response to the newly emerging field of studies: Applied Computer Science. The new department combines several areas of computer science research under one roof in the Faculty of Geology, Geophysics and Environmental Protection. In 2006, the department changed its name to the Department of Geoinformatics and Applied Computer Science as part of faculty reorganization. The Head of the Department of Informatics in Earth Sciences was Professor AGH Andrzej Leśniak, $\mathrm{PhD}$, who was also appointed at that time as the Vice Dean of the Faculty of Geology, Geophysics and Environmental Protection. Professor Andrzej Leśniak has been Head of the department since the formation of the department.

The department assembles prominent scientific and didactic specialists in emerging technologies and scientific issues related to a broad understanding of computer science in Earth and Environmental Sciences. Research workers are members of reputable international scientific and industrial organizations, for example EAGE, IEEE, and SPE. There are currently $14 \mathrm{PhD}$ students in earth sciences (geology, geophysics) and technical sciences (mining and geological engineering). In geoinformatics, our $\mathrm{PhD}$ students defend theses in technical sciences (geodesy and cartography) at the Faculty of Mining Surveying and Environmental Engineering at AGH University of Science and Technology.

\section{RESEARCH AREAS/ RESEARCH GROUPS}

The Department of Geoinformatics and Applied Computer Science carries out research in:

- geoinformatics, GIS, remote sensing,

- computer graphics,

- numerical modeling of geodynamic phenomena,

- modeling in distributed environments,

- analysis and processing of digital images,

- artificial intelligence,

- computer science in environmental protection,

- statistical methods, data mining, and big data in Earth sciences,

- databases, data warehousing, data banks,

- computer networks.

All research carried out in the department takes into account the specificities of environmental, geological and geophysical data and the latest global trends in technical and natural sciences. Department staff is actively involved in many research projects as part of national and international grants and statutory research. Projects that should be mentioned include European Space Agency (ESA) funding programs, European Erasmus+ grants, the National Centre for Research and Development (NCBR) Demonstrator and Leader competitions, and, from the Programme of Applied Research, National Science Centre (NCN) OPUS and PRELUDE competitions.

The most interesting are:

- research in the development of a comprehensive system for continuous monitoring of static and dynamic state of earthen flood embankments, with the ability to simulate structural changes and estimate damage risk (National Centre for Research and Development); 
- development of solutions to optimize the deployment of traffic management and medical rescue teams operating in the province of Małopolska (Treasury-Governor of Małopolska Jerzy Miller),

- The use of stochastic methods in the evaluation of the symmetry of anisotropic mediums on the basis of full tensor flexibility (National Science Center),

- Decomposition methods of four-polarimetric SAR data based on pattern recognition (European Space Agency).

\section{FACILITIES}

The Department of Geoinformatics and Applied Computer Science has two specialized computer laboratories. The first has multimedia equipment, air conditioning, and 30 computer stations equipped with high quality desktop PCs with i7 processors and specialized software for teaching informatics and geoinformatics. The second laboratory is the students' computer measurement systems laboratory, where students become familiar with electronics, computer architecture, computer networks, and measurement systems.

The Department has a modern IBM Blade-type server system. The system is composed of 14 dedicated machines, each with two quad-core Intel processors and 16GB of RAM. All are connected to a fast internal Ethernet network, which allows for very efficient communication between servers. Moreover, the Department has three Blade graphic stations equipped with modern NVIDIA Quadro graphic cards that are capable of 80 Gflop floating-point operations per second. Overall, the available computational speed is sufficient for efficient processing of the complicated computational problems that are often encountered in Earth sciences.

\section{EDUCATION}

\section{AND TEACHING OFFERS}

Full-time undergraduate degree (BSc) and second degree studies (Master complementary) in Applied Computer Science are offered in Faculty of Geology, Geophysics and Environmental Protection. The second degree studies are offered in three specialties: Geoinformatics, Software and Databases in Geology and Modelling and Information Systems in Geophysics. All three specializations prepare graduates for work as experts in applied computer science with extended earth science knowledge, especially geology, geophysics and environmental research.

Geoinformatics specialists can master knowledge of methods for creating and managing spatial databases and geoinformation systems. Graduates are specialists in the latest tools and methods for processing and analyzing geospatial data, including satellite remote sensing and aerial data.

Another specialty is Software and Databases in Geology. This specialty is very popular among students as, for example, it teaches them to create, use and manage extensive databases in various fields of economy, industry and state or local administration. Upon graduation, students find work as developers of complex systems or database designers.

The third specialty is Modelling and Information Systems in Geophysics. Students learn to create distributed systems software and administration systems. Skills that allow students to find creative solutions to problems using modeling and numerical methods are also taught.

As part of Applied Computer Science studies, students acquire specialized knowledge of computer science and information technology applications in the Earth Sciences.

In the first cycle of studies (BSc), over 50\% of courses are from the canon of computer sciences, less than $5 \%$ are geoinformatics courses, $25 \%$ are from the general canon of technical science at AGH University of Science and Technology (including mathematics, physics and chemistry). The remaining $20 \%$ of classes are apprenticeships, diploma seminars, foreign languages and physical education.

In the second stage of studies, the number of computer science and geoinformatics courses is higher, with the total number of courses exceeding $70 \%$.

Study programs conducted by the Department of Geoinformatics and Applied Computer Science are evaluated by the Career Centre by questioning graduates about their careers a few months after graduation. 
One year after graduation, over $94 \%$ of graduates are employed in computer science professions (according to reports from 2012 and 2015 compiled by AGH Career Centre).

Our best graduates often do not need to seek work. Apprenticeships, internships, and work in science clubs allow them to make connections with future employers; more than $30 \%$ of graduates receive direct job offers from employers.

In addition, it should be emphasized that our third year BSc studies students work part-time or full-time in relevant professions.

In the second cycle of studies at the Faculty of Geology, Geophysics and Environmental Protection, the Department of Geoinformatics and Applied Computer Science offers specialization in the field of Environmental Protection. This specialization is realized in cooperation with the Department of Hydrogeology and Engineering Geology and the Department of Environmental Protection. The Department also conducts classes in computer science methods for other fields of study at the Faculty of Geology, Geophysics and Environmental Protection. Additionally, in cooperation with the Faculty of Metals Engineering and Industrial Computer Science, students are educated in stage I and II studies in Computational Engineering.

With the formation of the Department of Geoinformatics and Applied Computer Science, the "Geos Informatica" Science Club was created under the initiative of students. The club was established in 2002 under the auspices of the Department of Geoinformatics and Applied Computer Science at the Faculty of Geology, Geophysics and Environmental Protection, AGH. MSc. Kamil Szostek is the mentor of "Geos Informatica" Science Club. Members of the club create innovative projects and solve scientific problems. The most important of these is a project developed in collaboration with the Office of the Provincial city of Krakow: "Developing solutions to optimize the deployment of traffic management and medical rescue teams operating in the province of Małopolska”. Members arrange lectures, workshops and lectures for students of not only computer science. Since the club was formed, active
"Geos Informatica" members have taken first and third place in 52 and first place in 53 Scientific Club Sessions.

\section{COOPERATION}

Since the Department of Geoinformatics and Applied Computer Science was founded, action has been taken to establish sustained cooperation with other industrial and scientific institutions, both domestically and abroad. The department cooperates with the Department of Geology at the Technische Universitat Bergakademie in Freiberg, Germany. As part of this cooperation, scientists from the Department of Geoscience Institute of Mathematics and Informatics at TU Bergakademie conduct guest lectures for level II and III degree students. Other research units cooperating with KGiIS include the Geological Institute Warsaw, the Krakow Institute of Oil and Gas, the Institute of Geological Sciences Research Centre in Krakow, the Institute of Geophysics, CINECA in Bologna Italy, the Institute of Archaeology at the Academy of Sciences of the Czech Republic, and the Memorial University of Newfoundland, Canada.

With the participation of employees of the Department of Geoinformatics and Applied Computer Science, the Satim Satellite Monitoring spin-off company was formed, which is the first Polish company that uses satellite and aerial imaging (both radar and optical) in environmental applications. As part of the company's operations, research is carried out in, among others, natural hazards, the impact of mining on the environment, changes in land use, urban sprawl, the stability of buildings, and the infrastructure and deformation of roads.

The department employees are members of renowned national and international scientific and industrial organizations, such as the European Association of Geoscientists and Engineers (EAGE), the Institute of Electrical and Electronics Engineers (IEEE), the Society of Petroleum Engineers (SPE), the Polish Academy of Sciences (PAS), the Polish Academy of Arts and Sciences (PAAS), and the Polish Association for Spatial Information (PASI). 